\title{
Specific Monosynaptic Sensory-Motor Connections Form in the Absence of Patterned Neural Activity and Motoneuronal Cell Death
}

\author{
Bruce Mendelson and Eric Frank \\ Department of Neurobiology, Anatomy, and Cell Science, University of Pittsburgh School of Medicine, Pittsburgh, \\ Pennsylvania 15261
}

The importance of neural activity and motoneuronal cell death in the formation of specific synaptic connections between muscle afferents and motoneurons was studied in chick embryos. Patterned neural activity was blocked by applying $d$-tubocurarine (dtc) chronically to embryos during the period when sensory-motor connections are formed [stages (St) 28-42]. Dtc blocks neurogenic muscle contractions, thereby abolishing any temporal correlation between neural activity in motoneurons and stretch-sensitive afferents. The normal pattern of motoneuronal bursting is also blocked (Landmesser and Szente, 1986), as is motoneuronal cell death (Pittman and Oppenheim, 1979). Dtc applications were started more than $1 \mathrm{~d}$ before muscle sensory afferent collaterals make anatomical contact with motoneuronal dendrites and continued until St 38-42, when the pattern of synaptic connectivity was examined by recording synaptic potentials intracellularly from identified lumbosacral motoneurons upon stimulation of identified populations of muscle afferents. In both normal and dtc-treated animals, large monosynaptic excitatory potentials were evoked in homonymous motoneurons (those that supply the same muscle as the sensory afferents) and were often observed in motoneurons that supplied synergistic muscles. Monosynaptic potentials were uncommon in motoneurons supplying antagonistic muscles. The overt patterns of sensory-motor connections in normal and dtc-treated embryos were essentially identical. However, the amplitudes of the composite EPSPs recorded in dtc-treated animals were consistently about twice as large as normal. These observations suggest that neither normal patterns of neuronal activity nor motoneuronal cell death play a large role in determining the specificity of connections between the sensory and motor neurons involved in the stretch reflex.

An important unanswered question in developmental biology is how nerve cells make specific connections with their targets. The development of these connections can be divided into at least two phases: growth of neuronal processes to the target area and synapse formation between particular neurons and partic-

\footnotetext{
Received Oct. 1, 1990; revised Nov. 26, 1990; accepted Dec. 7, 1990.

It is a pleasure to thank Laurie Corwin and Farzin Hashemi for their excellent technical assistance. This work was supported by a grant from the National Science Foundation to E.F. and by a Grass Fellowship to B.M.

Correspondence should be addressed to Bruce Mendelson, Department of Anatomy (\#510), University of Arkansas for Medical Sciences, 4301 West Markham St., Little Rock, AR 72205-7199.

Copyright (C) 1991 Society for Neuroscience $0270-6474 / 91 / 111390-14 \$ 03.00 / 0$
}

ular target cells. The present study addresses the second phase of this process where neurons "choose" to form connections with only a specific subset of cells located among many inappropriate targets. This problem was approached by studying the development of the synaptic connections involved in the monosynaptic stretch reflex, a system where the individual neuronal elements are accessible to anatomical and electrophysiological study.

The stretch reflex is one of the simplest reflex arcs known in vertebrates and is well suited for developmental study. Sensory neurons supplying stretch-sensitive spindles in a skeletal muscle monosynaptically excite motoneurons supplying the same (homonymous) muscle, as well as motoneurons that contact synergistic muscles. These afferents often polysynaptically inhibit motoneurons projecting to antagonistic muscles. The high level of synaptic specificity in this system has been proposed to assist in locomotion (Eccles and Lundberg, 1958; Engberg and Lundberg, 1969; Fritz et al., 1989) and has been well documented in the cat (Eccles et al., 1957; Mendell and Henneman, 1971), the rat (Jahr and Yoshioka, 1986), the chick (Eide et al., 1982; Lee et al., 1988), and the frog (Frank and Westerfield, 1982).

Differences in temporal and spatial aspects of synapse formation may contribute to the specificity of the synaptic connections mediating this reflex, as suggested initially by Wyman (1974). These factors are unlikely to provide a complete developmental explanation for this specificity, however. In the bullfrog, dendrites of motoneurons supplying different muscles overlap extensively, as do the central projections of different muscle sensory afferents (Jhaveri and Frank, 1983; Lichtman ct al., 1984). Sensory afferents supplying different muscles in the bullfrog forelimb are also known to be generated during the same developmental period (Mendelson and Frank, 1990), and, later in development, the connections between these various afferents and brachial motoneurons form contemporaneously, showing a high level of specificity from the outset (Frank and Westerfield, 1983). These observations make it unlikely that differences in the positions of the postsynaptic target neurons, or differences in the times that specific sensory and motor neurons develop or form synaptic connections, can be entirely responsible for the establishment of synaptic specificity in this system.

In some parts of the developing nervous system, neural activity has been shown to influence the final pattern of synaptic connectivity (reviewed in Purves and Lichtman, 1984; see also Fawcett and O'Leary, 1985; Debski and Constantine-Paton, 1990). In these situations, synaptic connections among subsets of pre- and postsynaptic neurons that are electrically active si- 
multancously arc reinforced. This phenomenon has been demonstrated most elegantly in studies of the development of the vertebrate visual system. Changes in either the amount or the pattern of neural activity during development or regeneration of the visual system can induce drastic changes in axonal arborization and/or synaptic connectivity (Hubel and Wiesel, 1965; Meyer, 1983; Schmidt and Edwards, 1983; Stryker and Harris, 1986; Shatz and Stryker, 1988; Sretavan et al., 1988). In the context of the stretch reflex, neurogenic muscle movements in developing embryos could evoke activity in stretch-sensitive spindle afferents, and these temporally related pre- and postsynaptic activity patterns might influence the choice of connections between these neurons in the spinal cord.

On the other hand, a complete blockade of neural activity during amphibian embryonic development apparently has little effect on the development of the synaptic connections necessary for coordinated swimming bchavior (Harrison, 1904; Carmichael, 1926, 1927; Matthews and Detwiler, 1926; Haverkamp, 1986; Haverkamp and Oppenheim, 1986), and at least some spinal cord circuitry in the chick forms in an environment of abnormal neural activity (Landmesser and Szente, 1986). The importance of patterned neural activity during synaptogenesis thus appears to differ in different regions of the nervous system. Perhaps different types of synaptic connections are specified by different mechanisms. It is therefore of interest to determine the role of neural activity in the specification of the connections between sensory and motor neurons involved in the stretch reflex.

In the present experiments, activity patterns were altered in developing chick embryos by injecting $d$-tubocurarine (dtc) into eggs during the period when sensory-motor connections are formed [stages (St) 28-42]. This procedure blocks all neurogenic muscle contractions as well as a major fraction of the motoneuronal activity (Landmesser and Szente, 1986), thereby abolishing temporal correlations between activity in motor and stretch-sensitive sensory neurons. The results show that these treatments still permit the development of nearly normal patterns of sensory-motor connections.

Related experiments on the development of stretch reflexes in frogs suggested that synaptic specificity in this system was also independent of normal activity patterns in muscle sensory fibers (Frank, 1990). As discussed below, however, the experimental paradigm did not permit a complete analysis of the pattern of these connections.

Some of the present work has appeared previously in abstract form (Mendelson and Frank, 1989).

\section{Materials and Methods}

Animals. White Leghorn chick embryos were obtained from a local supplier. They were incubated at $37^{\circ} \mathrm{C}$ in a forced draft incubator and staged according to Hamburger and Hamilton (1951).

Electrophysiology. To assay the specificity and strength of synaptic connections between specific populations of sensory afferents and spinal motoneurons, we made electrical recordings from motoneurons in an isolated spinal cord preparation. Chick embryos were anesthetized by cooling the eggs for $20 \mathrm{~min}$ in ice water. The embryos were then removed and placed into a $10-12^{\circ} \mathrm{C}$ bath of recirculating, oxygenated $\left(95 \% \mathrm{O}_{2}\right.$, $5 \% \mathrm{CO}_{2}$ ) Tyrode's solution of the following composition (mM): $\mathrm{NaCl}$, 139; $\mathrm{KCl}, 3 ; \mathrm{CaCl}_{2}, 3 ; \mathrm{MgCl}_{2}, 1 ; \mathrm{NaHCO}_{3}, 17 ;$ glucose, $12.2(\mathrm{pH}, 7.2)$. Animals were decapitated, eviscerated, and skinned, and a ventral laminectomy was performed to expose the spinal cord. One side of the animal was subsequently removed, and the spinal cord was hemisected longitudinally along the dorsal-ventral midline. Individual peripheral nerves were dissected, and the lumbosacral (LS) spinal cord with dorsal root ganglia (DRG) and peripheral nerves intact was removed and placed in an experimental chamber for recording, where it was superfused with Tyrode's solution (Fig. 1). The temperature was slowly increased to $22^{\circ} \mathrm{C}$ and was maintained at this level for the duration of the recording session. Individual peripheral nerves were drawn into suction electrodes. Spinal neurons were impaled with glass micropipettes with tips filled with $0.15 \mathrm{M} \mathrm{KCl}$ and shanks filled with $2.0 \mathrm{M} \mathrm{K}^{+}$-methylsulfate $(0.5 \%$ fast green was added to both solutions to render the electrode tip visible). Pipettes were beveled to $90-130 \mathrm{M} \Omega$ shortly before use.

Lumbosacral motoneurons were identified by antidromic activation from one of the muscle nerves. Only those data from cells that had resting potentials more negative than $-40 \mathrm{mV}$ were analyzed. Synaptic potentials were recorded in response to the stimulation of sensory axons in individual muscle nerves. In this manner, the composite synaptic potentials elicited in an individual motoneuron by an identified population of muscle sensory afferents were recorded. The nerves were stimulated at frequencies of $1-2 \mathrm{~Hz}$, and the resulting synaptic potentials were averaged and stored digitally. The evoked responses included both excitatory and inhibitory potentials. The latencies of the different components of the synaptic potentials were measured with respect to peripheral nerve stimulation. Histograms of these latencies produced by stimulation of a specific muscle nerve (in animals of a given stage) showed clear bi- or multimodal distributions (Fig. $2 A$ ). The first mode in each distribution likely represents monosynaptic inputs (Eide et al., 1982; Lee et al., 1988): they began about $5 \mathrm{msec}$ after the arrival of the afferent volleys (recorded from the appropriate dorsal root or DRG) and were resistant to fatigue at $1-2 \mathrm{~Hz}$. The later modes, consisting of both EPSPs and IPSPs, fatigued rapidly at $1-2 \mathrm{~Hz}$ and presumably represent polysynaptic input to motoneurons.

Because sensory and motor axons are not completely myelinated at the stages (St 37-42) that electrophysiological recordings were made (Geren, 1955; Carpenter and Bergland, 1957), in one series of animals we recorded the afferent volley in the dorsal root evoked by stimulation of specific muscle nerves. Muscle nerves in three embryos at St 40 [embryonic day 14 (E14)] each gave a similar response that consisted of a large early wave with a conduction velocity of about $0.5 \mathrm{~m} / \mathrm{sec}$ and a smaller, longer-latency broader wave (Fig. $2 B$ ). Because Ia axons are the fastest-conducting sensory fibers in other systems, it is likely that the early wave contains the spindle afferents. The short-latency wave dominated the response in muscle (but not cutaneous) nerves, so the majority of the Ia spindle afferents are probably included in this wave. However, it is possible that some late-developing (and thus smallercaliber) Ia axons are excluded.

Because sensory axonal conduction velocities differed in animals of different stages, the average latencies of synaptic potentials were variable. To standardize our analyses, a monosynaptic model (Sah and Frank, 1984) was defined for each animal: A short-latency, fatigue-resistant EPSP was stored in the computer in such a way that it could subsequently be superimposed on all other traces during data analysis. Any synaptic potential with a latency more than $4 \mathrm{msec}$ longer than the model was defined as polysynaptic. In some embryos, monosynaptic models were defined for individual muscle nerves because the dissected nerves differed in length, and thus, conduction time varied among nerves. The monosynaptic potentials defined in this manner formed a discrete population of fatigue-resistant EPSPs that corresponded well with the EPSPs making up the earliest modes in the latency histograms described above.

There were some difficulties involved in measuring the amplitudes of homonymous inputs (synaptic potentials elicited by stimulating sensory afferents supplying the same muscle as the motor neuron under study). At stimulus strengths sufficient to activate all muscle afferents, an antidromic action potential was also elicited, and this obscured the synaptic potential. In most cases, submaximal synaptic potentials were measured by stimulating below the antidromic threshold, but at a strength sufficient to activate some muscle afferents. In other situations, impulse conduction in motor axons was blocked by reversing the stimulus polarity at a strength that activated most sensory axons, making it possible to observe the homonymous input. These methods consistently underestimated the amplitudes of homonymous inputs. However, even with these difficulties, monosynaptic EPSPs were observed in the majority of homonymous sensory motor pairs and were among the largest EPSPs recorded (see Results).

For convenience in describing the amplitudes of the synaptic potentials, we refer in the text to synaptic inputs with amplitudes less than $0.2 \mathrm{mV}$ as "no input." That is, the statement "homonymous inputs were recorded in all but $4 \%$ of the motoneurons" means that $4 \%$ of the 


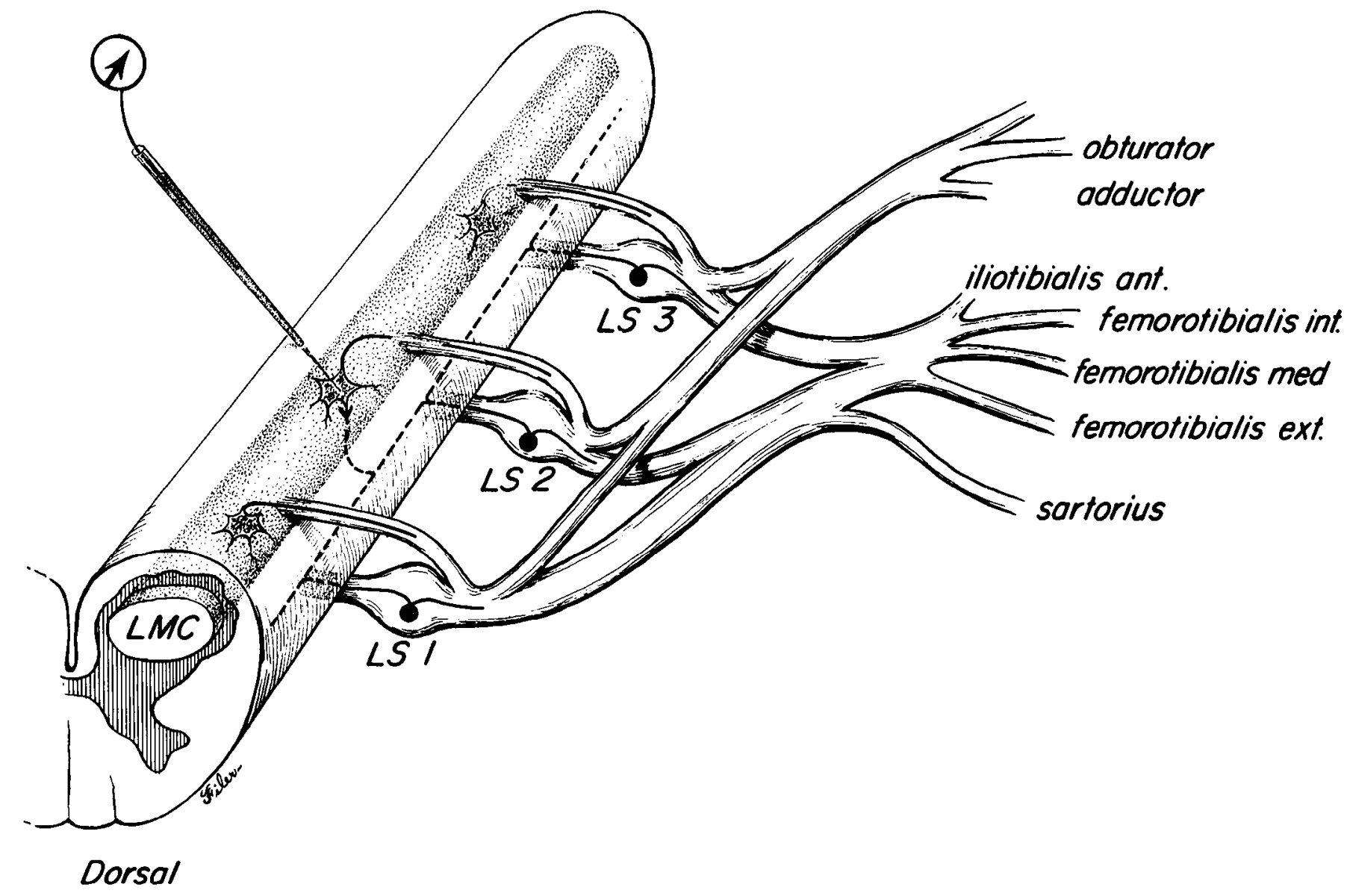

Figure 1. Schematic drawing (ventral view) of the isolated spinal cord preparation with dissected muscle nerves of the crural plexus. Intracellular recordings were made from motoneurons located in the lateral motor column $(L M C)$. Motoneurons were identified by antidromic activation from one of the muscle nerves, and synaptic potentials were subsequently recorded in response to electrical stimulation of sensory afferents with axons in individual muscle nerves. Not all nerve branches of the crural plexus are shown. The $L S$ spinal cord segments that contribute to the crural plexus are indicated.

motoneurons had homonymous inputs $<0.2 \mathrm{mV}$. Of course, inputs less than this arbitrary cutoff may be quite real. Therefore, the actual measurements were always used in determining average potential amplitudes. All amplitude values given in the text are the average values for the entire group.

Anatomy. To examine the detailed anatomy of sensory afferent arbors and motoneuronal dendrites, we labeled individual muscle nerves with the fluorescent marker 1,1'-dioctadecyl-3,3,3'3'-tetramethylindocarbocyanine perchlorate (DiI; Molecular Probes Inc.). Some animals were perfused with $20 \mathrm{ml}$ of Tyrode's solution followed by $20 \mathrm{ml}$ of $4 \%$ paraformaldehyde in $0.1 \mathrm{~m}$ phosphate buffer $(\mathrm{pH}, 7.3)$, and the spinal cords with peripheral nerves and DRGs intact were dissected. In other cases, the spinal cords that had been used for electrophysiological recording were immersed in the same fixative. After fixation, an individual muscle nerve was placed in a cuff containing DiI (about 10\%) in ethanol. The ethanol was allowed to evaporate, leaving crystals of DiI on the nerve, which was subsequently pinned out away from the remaining tissue. The spinal cords were stored in $4 \%$ paraformaldehyde in the dark at $37^{\circ} \mathrm{C}$ for $1-6$ weeks to allow diffusion of the label. Vibratome sections were cut at $50-100 \mu \mathrm{m}$ and were mounted in serial order in phosphate buffer. The staining patterns were observed and photographed with a compound microscope equipped with epifluorescent illumination and a rhodamine filter set. In selected sections, the DiI fluorescence was photoconverted to a permanent reaction product (Sandell and Masland, 1988). Briefly, the sections were placed in a depression slide and incubated in a solution of $150 \mathrm{mg}$ diaminobenzidine $/ 100 \mathrm{ml}$ Tris buffer $(\mathrm{pH}, 8.2)$ on ice for $30 \mathrm{~min}$. A selected region of the section was then illuminated with a rhodamine filter set for $15-40 \mathrm{~min}$ with an Olympus
D-Plan Apo $20 \times$ objective ( 0.7 NA). These photoconverted sections were counterstained with neutral red, dehydrated, and coverslipped with Permount.

Drug administration. To assess the role of neural activity on the formation of synaptic connections between sensory and motor neurons, we blocked neuromuscular transmission with $d$-tubocurarine (dtc) at critical developmental times. A window in each egg was made at E3 (St 19-20) and sealed with a coverslip and melted paraffin. The dtc, dissolved in sterile Tyrode's solution $(10 \mathrm{mg} / \mathrm{ml})$, was administered daily through the window, which was subsequently resealed. Doses of 1.5-3 $\mathrm{mg}$ dtc were applied directly to the well-vascularized chorioallantoic membrane. These dosages have previously been shown to block neuromuscular activity and motoneuronal cell death (Pittman and Oppenheim, 1979; Landmesser and Szente, 1986). The dtc treatments were started at St 28, at least 1 full day before any contact between muscle afferents and motoneurons has been observed anatomically or physiologically (see Results), and continued until St 38-42, when the electrophysiological analyses were performed. As has been noted previously (Landmesser and Szente, 1986), chronic administration of dtc produces an increase in mortality such that fewer than $50 \%$ of the embryos survived until the necessary stages. Control embryos received either no injections or injections of $0.1-0.3 \mathrm{ml}$ of sterile Tyrode's solution.

The effectiveness of the neuromuscular block was determined as described previously (Pittman and Oppenheim, 1979; Landmesser and Szente, 1986). Briefly, the number of hindlimb movements in dtc-treated and control embryos was scored for 2-3 min each day and compared to the numbers previously determined for normal chicks. The counting was done at $37^{\circ} \mathrm{C}$ just prior to the daily dtc administration (about 24 

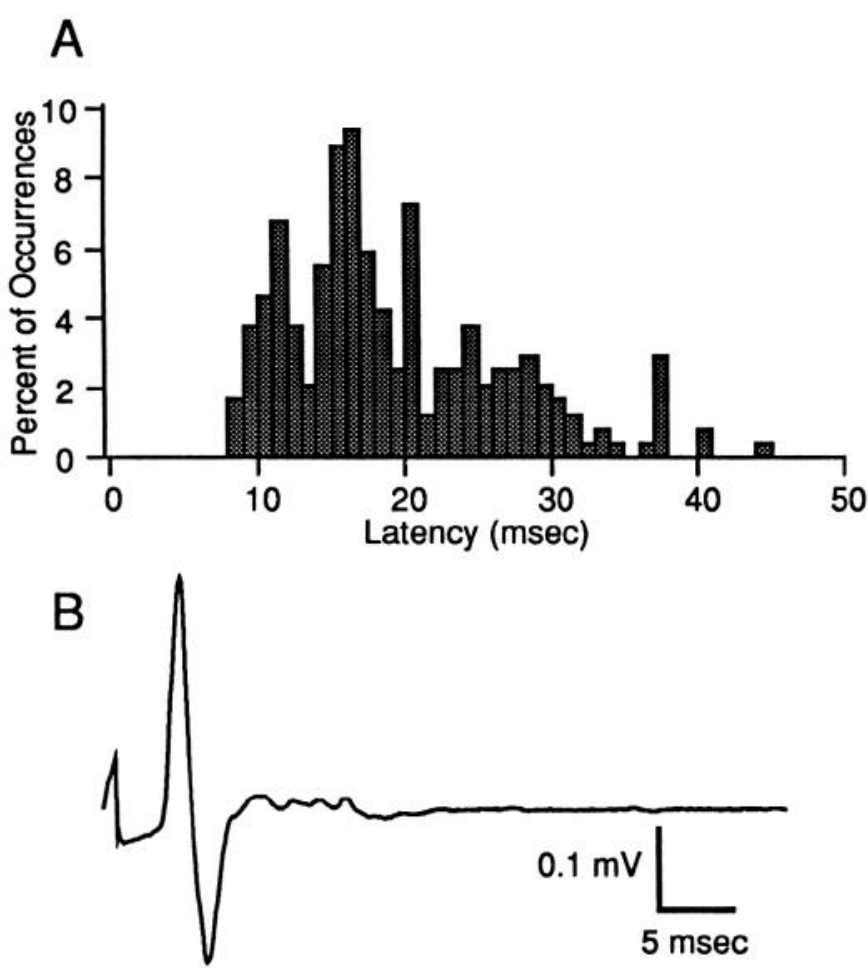

Figure 2. A, Latency histogram of Sart muscle sensory input to motoneurons in dtc-treated animals (146 motoneurons). Only heteronymous synaptic potentials are included because of the differing methods used to record homonymous potentials (see Materials and Methods). All components of the responses with amplitudes greater than $0.2 \mathrm{mV}$ are included; thus, if a motoneuron had early and late components, all are indicated. The histogram is multimodal. The first mode (at $\sim 12$ $\mathrm{msec}$ ) consists of EPSPs that were resistent to fatigue at $1 \mathrm{~Hz}$ and occurred about $5 \mathrm{msec}$ after the arrival of the afferent volley recorded in the dorsal root. These EPSPs were considered to be monosynaptic. The later modes, likely representing polysynaptic input, consisted of both EPSPs and IPSPs that fatigued quickly at $1-2 \mathrm{~Hz}$. $B$, Afferent volley recorded from the dorsal root of LS3 (see Fig. 1) upon stimulation of the aITB muscle nerve. The response consists of a single large compound action potential (conduction velocity about $0.5 \mathrm{~m} / \mathrm{sec}$ ) and a few smaller peaks representing more slowly conducting fibers. The trace is an average of five responses and is temporally aligned with the histogram in $A$.

$\mathrm{hr}$ after the previous dose). The numbers of motoneurons in the lumbosacral lateral motor columns (LMC) of some control and dtc-treated embryos were also determined. After electrophysiological analyses, spinal cords were fixed and embedded in paraffin. The cords were sectioned transversely at $15 \mu \mathrm{m}$ and stained with cresyl violet; the number of motoneurons in the LMC was then counted in one to three sections per segment of lumbosacral spinal cord. Only cells with clear nuclei and nucleoli were counted.

\section{Results}

Anatomy. To insure that the dtc blockade was effective throughout the time that synaptogenesis was occurring between muscle sensory and motor neurons, we used DiI to determine the time at which these sensory neurons first establish anatomical contact with motoneuronal dendrites. Exposure of individual muscle nerves to DiI in fixed embryos labeled sensory and motor somata at the appropriate segmental levels (Landmesser, 1978a;

Figure 3. Photomicrographs of the arborization patterns of muscle sensory afferents labeled at different developmental stages. $A$, Sart mus-
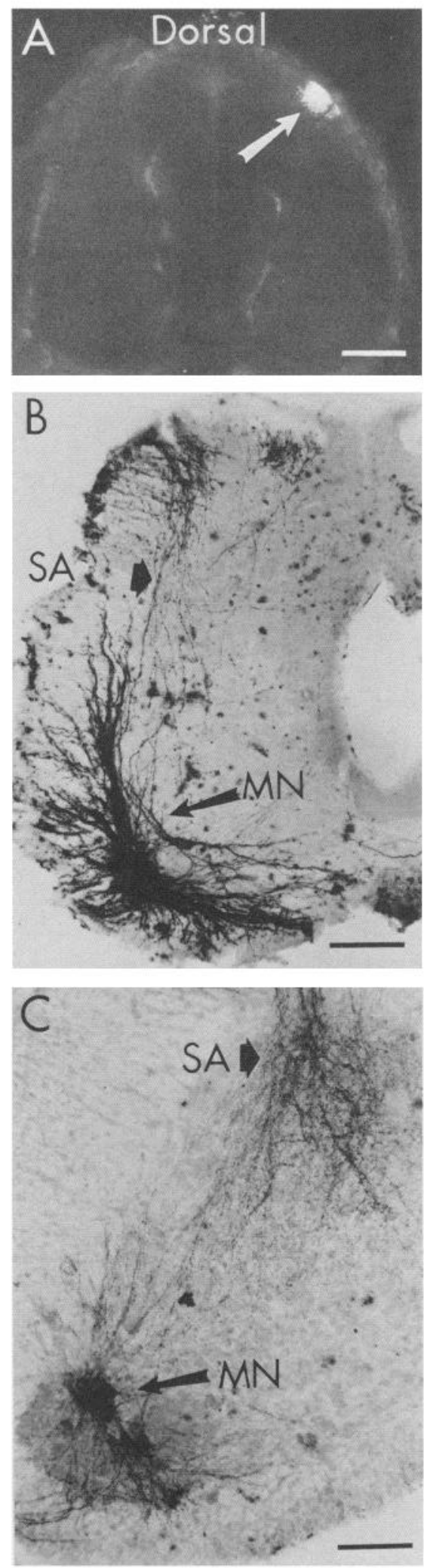

cle afferents labeled at E6 (St 28.5) are primarily confined to the oval bundle of His (arrow), the primordium of the dorsal columns. The section is taken about $100 \mu \mathrm{m}$ rostral of the Sart motor pool. $B$, At E8 (St 32), some Sart muscle afferent collaterals $(S A)$ overlap with dendrites of motoneurons $(M N) . C$, at E13 (St 39), mFT muscle afferent collaterals $(S A)$ arborize extensively in the region of motoneuronal dendrites, some collaterals extending ventrally into the LMC. Scale bars, $100 \mu \mathrm{m}$. 
Table 1. Muscles and their actions

\begin{tabular}{lll} 
Muscle & $\begin{array}{l}\text { Abbre- } \\
\text { viation }\end{array}$ & Action \\
\hline Sartorius (2 joint) & Sart & Hip flection, knee extension \\
Iliotibialis anterior (2 joint) & alTB & Hip flection \\
Femorotibialis external & eFT & Knee extension \\
Fcmorotibialis medial & $\mathrm{mFT}$ & Knee extension \\
Femorotibialis internal & iFT & Medial rotation of calf, weak knee extension \\
Adductor longus et brevis & Add & Hip extension* \\
Obturator (interior and exterior) & Obt & Hip rotation, hip abduction
\end{tabular}

* There is limited adduction in the bird hindlimb (Jacobson and Hollyday, 1982a; Raikow, 1985).

Hollyday, 1980; Honig, 1982) and, in addition, labeled the central projections of muscle afferents within the spinal cord (Fig. 3). We found that, though the initial projections into the spinal gray matter were observed about $12 \mathrm{hr}$ earlier than previously described, the development of central projections of identified muscle afferents was similar to that reported when all afferents of an LS segment were labeled (Lee et al., 1988; Davis et al., 1989). At E5.5-6 (St 28-29), the time that dtc injections were initiated, sartorius muscle afferents were present in the oval bundle of His (the primordium of the dorsal funiculus) for at least two segments rostral and caudal to their segment of entry. At these stages, ventral collaterals were just beginning to penetrate the gray matter of the superficial laminae (Fig. 3A). Motoneuronal dendrites were most prominent along the gray-white border, and the dorsal dendrites were at least $150 \mu \mathrm{m}$ ventral of the deepest-projecting muscle afferent collaterals. About $2 \mathrm{~d}$ later, at St 32-33 (Fig. 3B), the first overlap between sensory afferent collaterals and motoneuronal dendrites was observed. Therefore, dtc injections were started at least $1 \mathrm{~d}$ before the first anatomical contacts between sensory and motor neurons were observed.

At the time that electrophysiological recordings were made in the present study, muscle afferents had arborized in a specific pattern in the spinal cord. Labeling of either the Sart or Add muscle nerve (for abbreviations of muscles, refer to Table 1) in four animals at St 38 (E12) and 9 animals at St 40 (E14) showed that one population of collaterals entered the gray matter dorsomedially and descended unbranched through the dorsal horn to arborize primarily in two regions (Fig. 3C): (1) in and around lamina 6 in a column of large neurons, thought to be homologous to the nucleus dorsalis of Clarke (Leonard and Cohen, 1975; Martin, 1979) and (2) in the region of motoneuronal dendrites and somata in laminae 7 and 9. This pattern of arborization is similar to that described for physiologically identified muscle spindle afferents in the cat (Brown and Fyffe, 1978, 1981) and bullfrog (Lichtman et al., 1984), suggesting that muscle spindle afferents are included in this population.

Synaptic connections between muscle sensory and motor neurons. To analyze the pattern of connections between muscle sensory and motor neurons, we recorded intracellularly from antidromically identified motoneurons and stimulated individual muscle nerves. The synaptic responses consisted of shortlatency EPSPs that were resistant to fatigue at stimulus frequencies of $1-2 \mathrm{~Hz}$ and were frequently followed by longerlatency excitatory and inhibitory potentials, which tended to fatigue quickly. The short-latency EPSPs occurred shortly after the early wave of the afferent volley recorded in the dorsal root (see Fig. 2, Materials and Methods). For example, the monosynaptic potentials elicited in $\mathrm{eFT}$, $\mathrm{mFT}$, and $\mathrm{iFT}$ motoneurons upon eFT muscle nerve stimulation had an average latency of $12.0 \pm 1.8 \mathrm{msec}$ in normal embryos and $13.9 \pm 1.3 \mathrm{msec}$ in dtc-treated animals ( $\pm 1 \mathrm{SD} ; N=23$ and 29 , respectively). The rising phase of these EPSPs began about 4-8 msec after the arrival of the eFT afferent volley in the appropriate dorsal roots (3.6-8.3 msec; 3 animals). These latencies are similar to those described previously as monosynaptic (Eide et al., 1982; Lee et al., 1988). We will therefore refer to these short-latency, fatigueresistant EPSPs as monosynaptic (see Materials and Methods for a more detailed definition).

In normal embryos, 208 motoneurons supplying 7 different muscles were studied in 20 animals. In each motoneuron, the synaptic potentials elicited by the sensory afferents that supply these same muscles were digitized, averaged, and recorded. The monosynaptic components of these potentials were measured off line as described in Materials and Methods. The physiological functions of each muscle are listed in Table 1, while the

Table 2. Functional relationships among muscles

\begin{tabular}{llllllll} 
Muscle & Sart & aITB & eFT & mFT & iFT & Add & Obt \\
\hline Sart & hom & syn & weak syn & weak syn & weak syn & ant & \\
aITB & syn & hom & & & & ant \\
eFT & weak syn & & hom & syn & weak syn & \\
mFT & weak syn & & syn & hom & weak syn & \\
iFT & weak syn & & weak syn & weak syn & hom &
\end{tabular}

Add ant ant hom

Obt hom




\section{MUSCLE NERVE STIMULATED}

Normal Animals

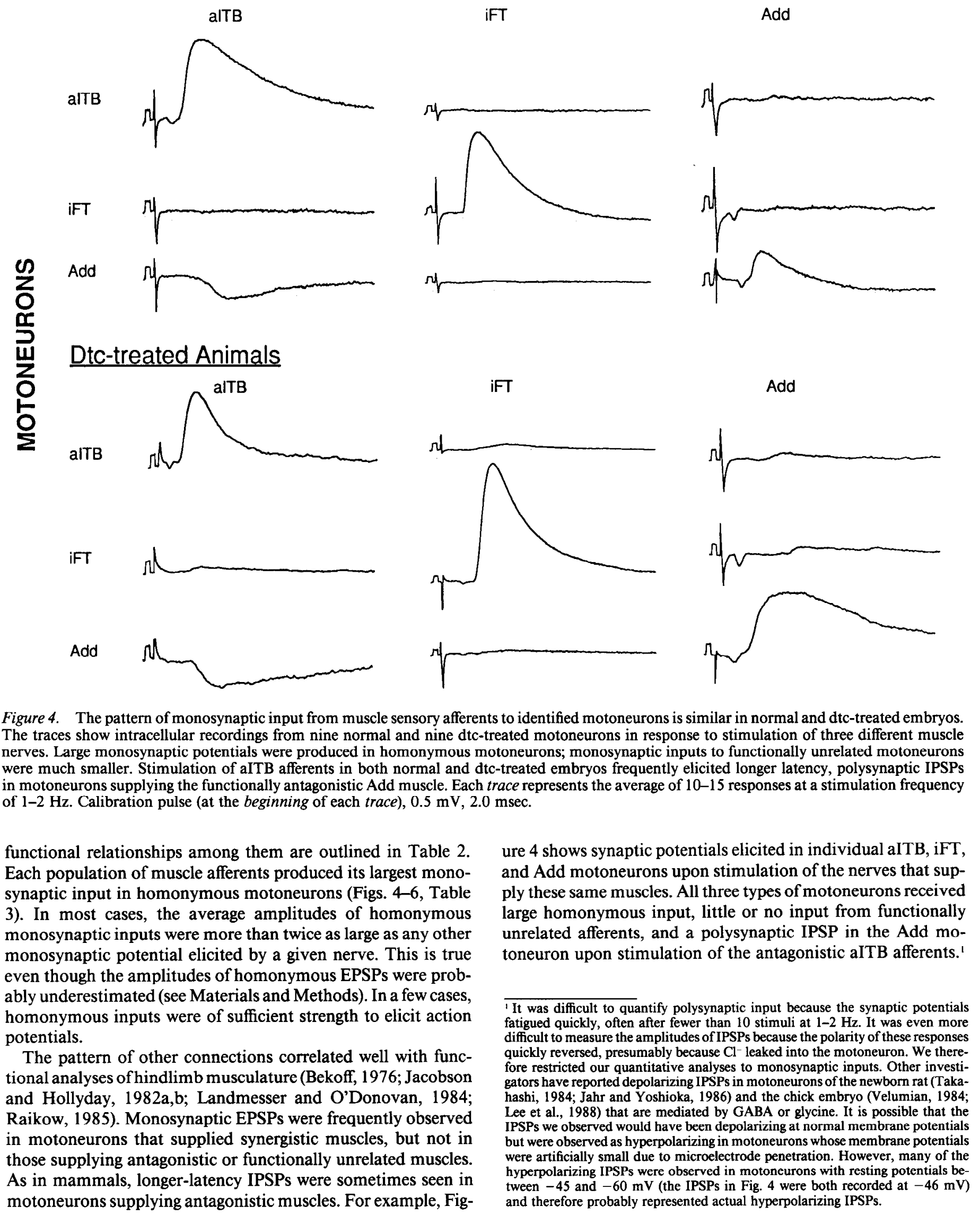




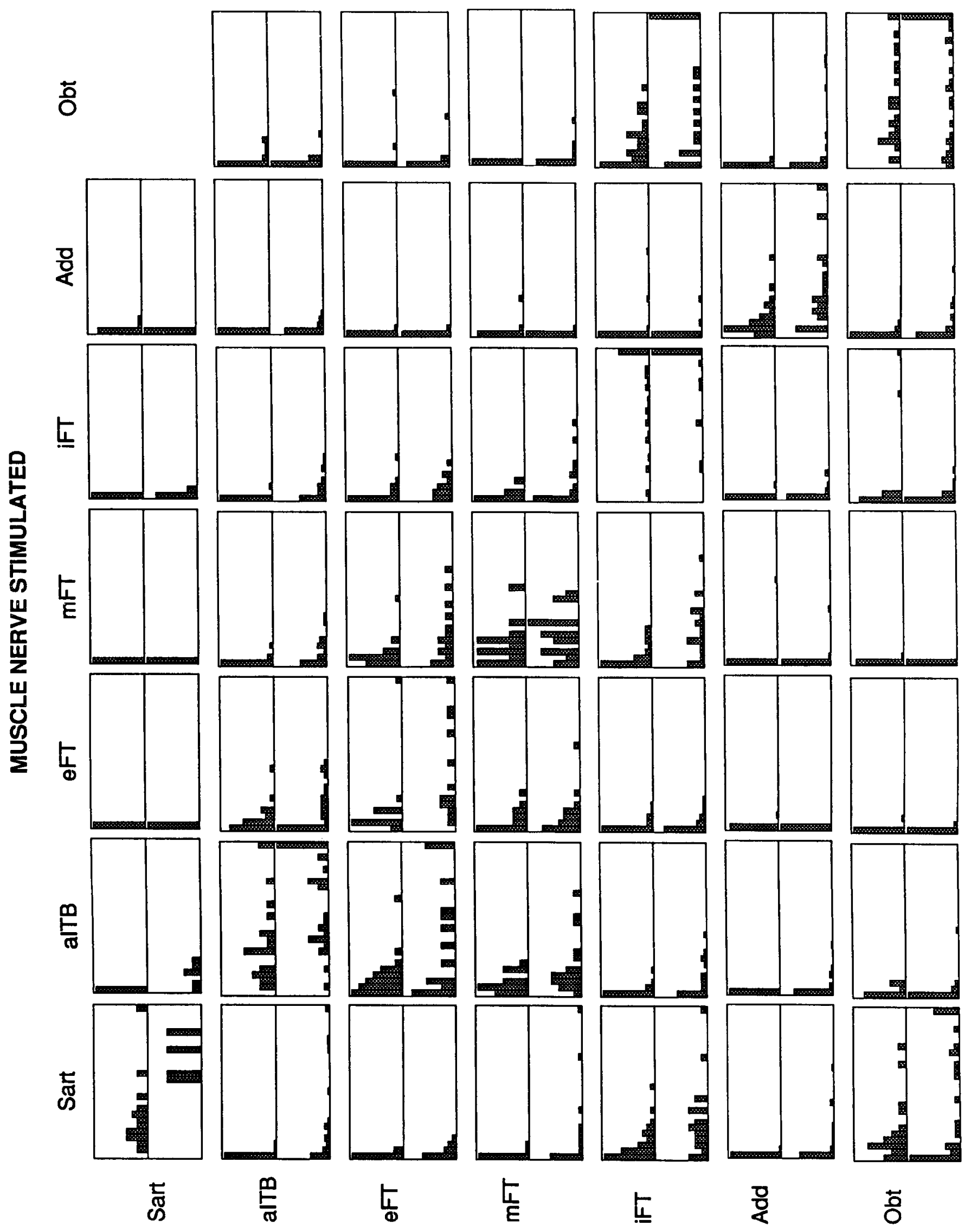




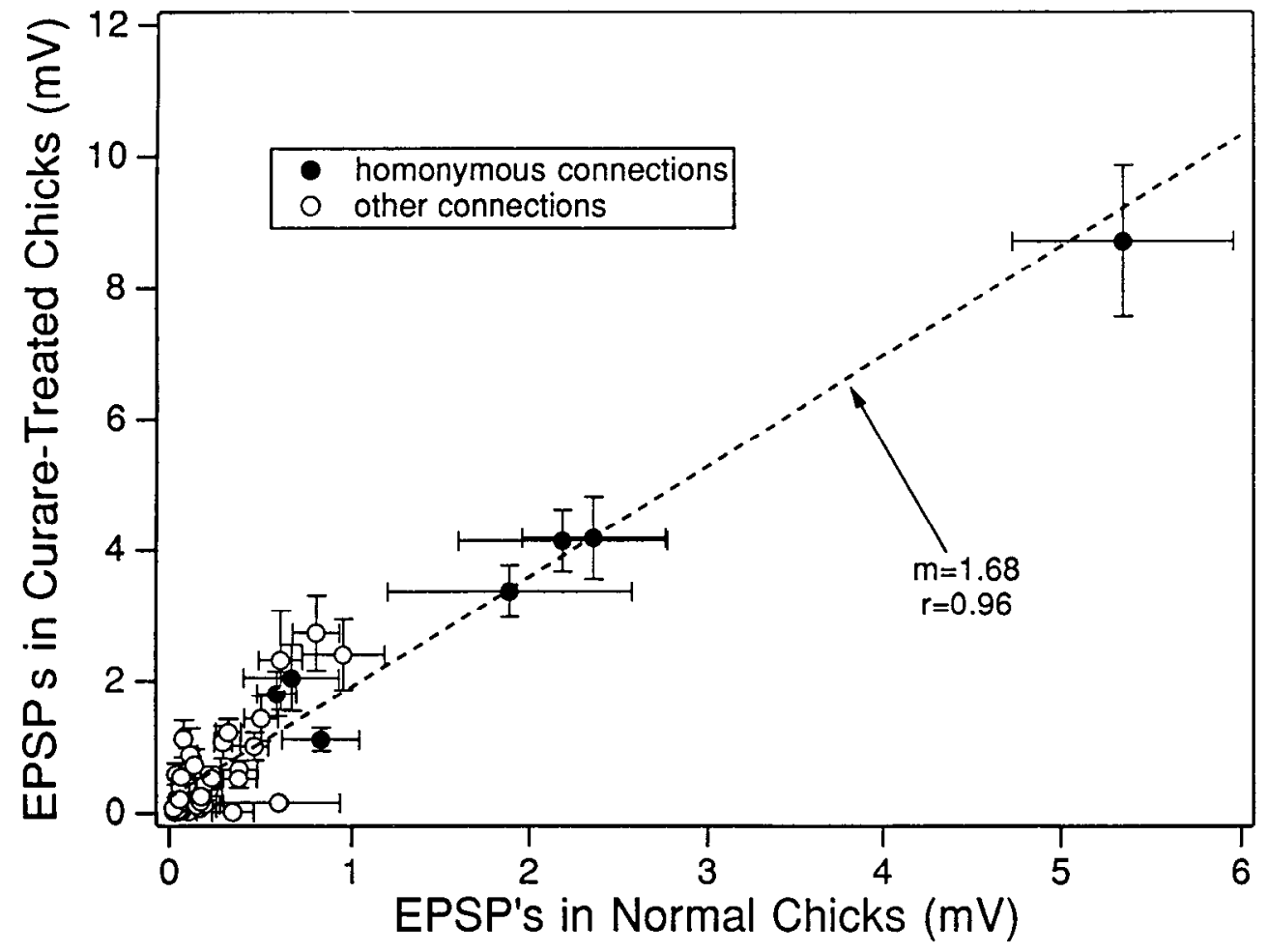

Figure 6. Correlation of monosynaptic EPSP amplitudes between normal and dtc-treated embryos. For each type of sensory-motor pair, the average EPSP amplitude ( $\pm 1 \mathrm{SE}$ ) in normal embryos is plotted against the corresponding value in dtc-treated embryos. Homonymous inputs are indicated by solid symbols; all others, by open symbols. The broken line is a least-squares linear regression for all the data; $m$ is the slope, and $r$ is the correlation coefficient.
Monosynaptic EPSPs were consistently observed among the neurons supplying the various femorotibialis muscle heads (Fig. 5 , Table 3). This relationship was expected between eFT and mFT, both knee extensors, but was not predicted between either of these muscles and iFT because iFT is primarily a calf rotator. Another set of interesting connections that occurred bidirectionally at a high frequency were those between aITB, a hip flexor, and all three types of femorotibialis neurons. These muscles are not mechanical synergists, but they may be related functionally because they are coactivated during the swing-extension phase of walking in hatchlings (Jacobson and Hollyday, 1982a; see also Table 2).

Development of dtc-treated embryos. To explore the importance of patterned and temporally correlated neural activity on the development of this synaptic pathway, we chronically treated one set of embryos with the neurosmuscular blocking agent dtc. As has been previously reported (Laing and Prestige, 1978; Pittman and Oppenheim, 1979; Landmesser and Szente, 1986), chronic exposure to dtc not only greatly reduces embryonic motility, but also prevents the naturally occurring death of about $50 \%$ of the motoneurons generated. To assess the effectiveness of dtc treatment, we measured the frequency of hindlimb movements (in ovo) and numbers of motoneurons (Table 4). Motility was greatly reduced in dtc-treated embryos, and the few movements that did occur were of smaller amplitude than normal, consisting of small twitches that did not alter joint angles to a large extent. There was thus little change in the length of individual muscles in dtc-treated embryos and, presumably, little or no stretch-evoked activity in muscle spindle afferents. ${ }^{2}$ The treatment should therefore have abolished temporal correlations of neural activity between motor and stretch-sensitive sensory neurons.

The reduction of motoneuronal death that occurs in dtc-treated animals has been well documented (Pittman and Oppenheim, 1978, 1979; Oppenheim and Chu-Wang, 1983). By counting all motoneurons with nucleoli in one or more sections in each of the first four segments of the LS spinal cord (the segments that give rise to the crural plexus; Fig. 1), we found 53\% more mo-

\footnotetext{
${ }^{2}$ There are also rhythmic contractions of smooth muscle cells in the amniotic membrane that are myogenic (Romanoff, 1960) and that move the embryo within the extraembryonic fluid. The rate of these contractions was variable, but was not decreased by chronic dtc treatment. In fact, the average number of amniotic contractions measured on E9-13 was $10.8 \pm 5.3$ contractions $/ \mathrm{min}$ in dtc-treated embryos and $6.0 \pm 3.9$ in controls $( \pm 1 \mathrm{SD} ; N=18$ and 14 animals, respectively). These contractions may produce passive limb movements as the embryos are moved within the extraembryonic membranes, possibly leading to stretch-induced changes in spindle afferent activity. This activity would not, however, be correlated with activity in motoneurons.
}

Figure 5. Amplitude histograms of monosynaptic muscle sensory input to identified motoneurons. In each enclosed box, the top panel shows the inputs recorded from motoneurons in normal animals, and the bottom panel, those from dtc-treated embryos. The horizontal axes represent EPSP amplitude and run linearly from 0 to $5 \mathrm{mV}$ in $0.2-\mathrm{mV}$ bins; the right-hand bin represents responses $>5 \mathrm{mV}$. The vertical axes show the percentage of monosynaptic responses of different amplitude. The bins sum to $100 \%$ in each panel, and the vertical scales in each box (of two histograms) are identical. The pattern of monosynaptic input in normal and dtc-treated embryos is similar in almost all of the 48 types of sensory-motor pairs examined. However, the amplitudes of the responses are consistently larger in the dtc-treated animals. The largest monosynaptic inputs were recorded from homonymous and synergistic sensory-motor pairs. Average monosynaptic amplitudes and numbers of sensory-motor pairs tested for each type are given in Table 3. 
Table 3. Average amplitudes of monosynaptic sensory-motor connections

\begin{tabular}{|c|c|c|c|c|c|c|c|c|c|c|c|c|c|c|}
\hline \multirow[b]{3}{*}{ Motoneurons } & \multicolumn{14}{|c|}{ Muscle nerve stimulated } \\
\hline & \multicolumn{2}{|l|}{$\overline{\text { Sart }}$} & \multicolumn{2}{|l|}{ alTB } & \multicolumn{2}{|l|}{$\mathrm{eFT}$} & \multicolumn{2}{|l|}{$\mathrm{mFT}$} & \multicolumn{2}{|l|}{ iFT } & \multicolumn{2}{|l|}{ Add } & \multicolumn{2}{|l|}{ Obt } \\
\hline & $\begin{array}{l}\text { Nor- } \\
\text { mal }\end{array}$ & $\begin{array}{l}\text { dtc- } \\
\text { treat- } \\
\text { ed }\end{array}$ & $\begin{array}{l}\text { Nor- } \\
\text { mal }\end{array}$ & $\begin{array}{l}\text { dtc- } \\
\text { treat- } \\
\text { ed }\end{array}$ & $\begin{array}{l}\text { Nor- } \\
\text { mal }\end{array}$ & $\begin{array}{l}\text { dtc- } \\
\text { treat- } \\
\text { ed }\end{array}$ & $\begin{array}{l}\text { Nor- } \\
\text { mal }\end{array}$ & $\begin{array}{l}\text { dtc- } \\
\text { treat- } \\
\text { ed }\end{array}$ & $\begin{array}{l}\text { Nor- } \\
\text { mal }\end{array}$ & $\begin{array}{l}\text { dtc- } \\
\text { treat- } \\
\text { ed }\end{array}$ & $\begin{array}{l}\text { Nor- } \\
\text { mal }\end{array}$ & $\begin{array}{l}\text { dtc- } \\
\text { treat- } \\
\text { ed }\end{array}$ & $\begin{array}{l}\text { Nor- } \\
\text { mal }\end{array}$ & $\begin{array}{l}\text { dtc- } \\
\text { treat- } \\
\text { ed }\end{array}$ \\
\hline Sart EPSPs & 1.89 & 3.38 & 0.04 & 0.59 & 0.04 & 0.03 & 0.04 & 0.02 & 0.02 & 0.08 & 0.10 & 0.02 & & \\
\hline$N$ & 13 & 4 & 13 & 6 & 13 & 5 & 13 & 5 & 13 & 5 & 13 & 5 & & \\
\hline aITB EPSPs & 0.08 & 1.13 & 2.19 & 4.15 & 0.39 & 0.66 & 0.10 & 0.43 & 0.06 & 0.39 & 0.06 & 0.16 & 0.17 & 0.18 \\
\hline$N$ & 25 & 31 & 22 & 33 & 24 & 29 & 21 & 25 & 21 & 27 & 18 & 25 & 23 & 20 \\
\hline eFT EPSPs & 0.07 & 0.24 & 0.60 & 2.32 & 0.69 & 2.06 & 0.37 & 1.07 & 0.19 & 0.44 & 0.06 & 0.07 & 0.17 & 0.25 \\
\hline$N$ & 26 & 14 & 28 & 14 & 18 & 13 & 27 & 15 & 26 & 15 & 21 & 13 & 23 & 13 \\
\hline mFT EPSPs & 0.11 & 0.89 & 0.46 & 1.01 & 0.38 & 0.52 & 0.76 & 1.12 & 0.19 & 0.54 & 0.16 & 0.08 & 0.06 & 0.21 \\
\hline$N$ & 15 & 18 & 17 & 19 & 15 & 20 & 14 & 18 & 16 & 20 & 14 & 18 & 15 & 18 \\
\hline iFT EPSPs & 0.50 & 1.43 & 0.14 & 0.52 & 0.16 & 0.23 & 0.34 & 1.22 & 5.34 & 8.71 & 0.19 & 0.14 & 0.80 & 2.75 \\
\hline$N$ & 34 & 22 & 30 & 21 & 35 & 22 & 32 & 22 & 40 & 23 & 30 & 20 & 31 & 23 \\
\hline Add EPSPs & 0.06 & 0.44 & 0.05 & 0.22 & 0.07 & 0.04 & 0.16 & 0.12 & 0.05 & 0.13 & 0.58 & 1.80 & 0.07 & 0.55 \\
\hline$N$ & 24 & 27 & 23 & 27 & 22 & 27 & 24 & 26 & 26 & 26 & 28 & 27 & 25 & 25 \\
\hline Obt EPSPs & 0.95 & 2.41 & 0.17 & 0.19 & 0.07 & 0.06 & 0.08 & 0.06 & 0.60 & 0.15 & 0.10 & 0.32 & 2.36 & 4.19 \\
\hline$N$ & 20 & 31 & 20 & 33 & 20 & 32 & 21 & 32 & 21 & 32 & 20 & 33 & 25 & 36 \\
\hline
\end{tabular}

Data are the average monosynaptic EPSPs and the number of motoneurons $(N)$ recorded in normal and dtc-treated embryos.

toneurons in dtc-treated compared to normal embryos (Table 4), similar to the 50\% and 54\% increases Pittman and Oppenheim (1979) observed in the LMC of E13 and E16 embryos, respectively. In another series of embryos exposed to the same doses of dtc, we found a $64 \%$ increase in the number of brachial motoneurons ( $103.2 \pm 12.4$ motoneurons/section in 18 sections from six dtc-treated animals vs. $63.0 \pm 8.0$ cells in nine sections from three normal embryos). Both neurogenic muscle contractions and motoneuronal cell death were therefore drastically reduced during the time that monosynaptic connections between motor and sensory neurons were forming.

Sensorimotor connections. The pattern of muscle sensory input to the same seven types of motoneurons studied in normal embryos was determined in $10 \mathrm{dtc}$-treated animals. Intracellular recordings were made from 173 antidromically identified motoneurons. As in normal chicks, almost all neurons received strong homonymous monosynaptic inputs (Figs. 4-6); homonymous EPSPs were recorded in $97 \%$ of the motoneurons in dtctreated embryos as compared to $94 \%$ in normal embryos (Fig. 5 , Table 3 ). Table 3 shows that in all types of motoneuron the average amplitudes of monosynaptic homonymous inputs were more than twice as large as any synergistic input, and no homon- ymous inhibitory input was recorded in either dtc-treated or normal embryos.

The patterns of other monosynaptic inputs to motoneurons in dtc-treated embryos were also similar to normal (Figs. 4-6). Figure 4 shows that synaptic potentials elicited by stimulating three different muscle nerves in each of three different motoneurons in dtc-treated embryos are nearly identical to those in normal animals. These results are summarized in Figure 6, in which the average monosynaptic EPSP amplitude for each type of sensory-motor pair in dtc-treated animals is plotted against the corresponding amplitude in normal animals. The correlation coefficient for these data is 0.96 , indicating that there is a strong correlation between the amplitudes of synaptic potentials in dtctreated and normal embryos. This correlation can also be observed in the similarity of the normal and dtc-treated histograms of monosynaptic potential amplitudes recorded in the 48 different sensory-motor pairs (Fig. 5). For example, in every sensory-motor pair where monosynaptic input was present in more than $40 \%$ of the motoneurons in normal embryos, the same was true in dtc-treated animals.

Although the patterns of synaptic connections in the two groups of embryos were similar, the average amplitudes of the mono-

Table 4. Motility and numbers of motoneurons in normal and dtc-treated embryos

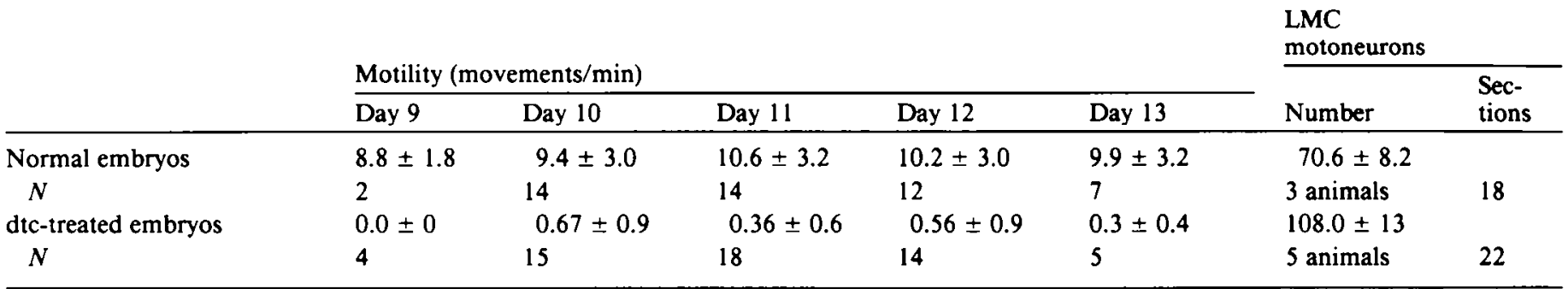

Values given are means $\pm 1 \mathrm{SD} ; N=$ number of animals. 
synaptic EPSPs in dtc-treated animals were consistently larger than normal. The slope of the broken line in Figure 6 (a leastsquares fit of the data) is 1.68 , indicating that the EPSPs in dtctreated animals are about $70 \%$ larger than the corresponding potentials in normal embryos. If homonymous potentials are excluded (because their amplitudes are difficult to quantify reliably), the slope of the line is 2.4, suggesting that EPSPs in dtctreated animals are actually more than double their normal size. The amplitude histograms in Figure 5 show that the increase in average amplitude is not due to a few very large EPSPs, but rather that most EPSPs were consistently larger than normal.

These differences in amplitude of monosynaptic connections may explain some of the subtle abnormalities observed in the connectivity patterns in dtc-treated embryos. For example, only $8 \%$ of the aITB motoneurons and $13 \%$ of the mFT cells received monosynaptic input from Sart muscle afferents in normal embryos $(0.08 \mathrm{mV} ; N=25$ and $0.11 \mathrm{mV}, N=15$, respectively; see Fig. 5, Table 3). However, in dtc-treated animals, $65 \%$ of the aITB and $44 \%$ of the mFT motoneurons were excited monosynaptically by Sart afferents $(1.13 \mathrm{mV}, N=31$ and $0.89 \mathrm{mV}$, $N=18$, respectively). The reciprocal situation also occurred with the aITB afferents in that none of the 13 normal Sart neurons received aITB input $(0.04 \mathrm{mV})$, while five of the six Sart neurons in dtc-treated animals did $(0.59 \mathrm{mV})$. Sart and aITB are both hip flexors and are therefore synergists (Table 2). The Sart muscle also acts to extend the knee and is thus a synergist of mFT. Because muscle spindle afferents often monosynaptically excite motoneurons supplying synergistic muscles, reciprocal connections would be expected. Perhaps the EPSPs observed in dtc-treated embryos represent connections that normally exist but are difficult to detect in normal embryos because of their small amplitudes.

Two other classes of monosynaptic connections were observed in dtc-treated animals that were not present in normal embryos. The hip flexors Sart and aITB are functional antagonists of Add, a hip extensor (Table 2). As would be expected, only $4 \%$ of the control Add motoneurons received Sart input (0.06 $\mathrm{mV}, N=24)$, and no inputs from aITB afferents were detected ( $0.05 \mathrm{mV}, N=23$; see Fig. 5, Table 3). However, in dtc-treated animals, $33 \%$ of the Add motoneurons received monosynaptic input from Sart, and $22 \%$ showed aITB input ( 0.44 and $0.22 \mathrm{mV}, N=27$ and 27 , respectively). These "aberrant" inputs are almost certainly monosynaptic because the average latency of the EPSPs was not longer than the input from these muscle afferents to motoneurons supplying the synergistic iFT muscle in the same embryos [for Sart muscle afferents, 11.5 $\pm 2.5 \mathrm{msec}$ in Add $(N=11)$ vs. $13.4 \pm 2.2 \mathrm{msec}$ in $\mathrm{iFT}(N=$ 20) motoneurons; for aITB muscle afferents, $9.6 \pm 1.2 \mathrm{msec}$ in Add $(N=6)$ vs. $13.1+1.8 \mathrm{msec}$ in iFT $(N=11)$ motoneurons; mean \pm 1 SD]. Despite these aberrant connections, however, the great majority of muscle sensory and motor neurons are connected appropriately in dtc-treated embryos.

\section{Discussion}

Anatomy. In the present study, neuromuscular activity was blocked with dtc during development to learn if specific connections between muscle sensory afferents and motoneurons would form in the absence of neurogenic muscle contractions. The neuromuscular blockade was started more than 1 full day before sensory afferent collaterals contact motoneuronal den- drites. Previous studies have documented the development of the central projections of sensory afferents by labeling all of the neurons in a given DRG with HRP (Lee et al., 1988; Davis et al., 1989) or with silver-staining techniques (Ramon y Cajal, 1929; Windle and Orr, 1934). However, labeling neurons with the fluorescent tracer DiI has proven to be a slightly more sensitive technique. For example, DiI labeling of an individual muscle nerve showed that afferent collaterals penetrated the spinal gray matter about $12 \mathrm{hr}$ earlier than previously reported (St 28, E5.5 vs. St 29, E6; Lee et al., 1988; Davis et al., 1989; Mendelson et al., 1990). Therefore, to confirm that monosynaptic connections between sensory and motor neurons had not formed at the time dtc injections were initiated, we labeled individual muscle nerves with $\mathrm{DiI}$ at different developmental stages. At the stage dtc injections were started ( $\mathrm{St} \mathrm{28)}$, muscle sensory and motor neurons have axons in the region of their target muscles (Landmesser and Morris, 1975; Landmesser, 1978b; Tosney and Landmesser, 1985). We were thus able to apply DiI to particular muscle nerves and show that, though the collaterals of identified populations of muscle afferents initiate growth into the gray matter earlier than previously reported, their overall pattern of development follows a similar time course to that described previously for all LS sensory neurons. For example, at St 28, muscle afferent growth cones were observed in the superficial laminae of the dorsal horn, but the most ventral collaterals were more than $150 \mu \mathrm{m}$ dorsal to motoneuronal dendrites. The first anatomical overlap of sensory afferent collaterals and motoneuronal dendrites was observed about 2 d later at St 32, the stage when short-latency synaptic potentials can first be recorded from ventral roots after stimulation of muscle afferents (Lee et al., 1988) and when reflexes can first be initiated (Windle and Orr, 1934; Visintini and LeviMontalcini, 1939). Therefore, dtc injections were started at least 1 full day before any monosynaptic sensory-motor connections have formed.

Electrophysiology of normal sensorimotor connections. The pattern of monosynaptic sensory-motor connections in the chick supports the hypothesis that Ia connections have developed to assist in locomotion (Eccles and Lundberg, 1958; Engberg and Lundberg, 1969; Fritz et al., 1989). As in other systems, the strongest inputs were recorded from homonymous sensory-motor pairs (Eccles et al., 1957; Frank and Westerfield, 1982). Monosynaptic inputs were also consistently recorded from synergists that act at the same joint, as in the case of eFT to mFT, where both types of afferents excited both types of motoneurons. There was little monosynaptic input to motoneurons that supplied functionally antagonistic muscles, and in some sensorymotor pairs, disynaptic or polysynaptic IPSPs were observed in antagonistic motoneurons. Polysynaptic inputs were difficult to quantify in this preparation, however, because they fatigued quickly and the polarity of the IPSPs frequently reversed shortly after the motoneurons were impaled.

Some excitatory connections were observed between muscles that act primarily at different joints. For example, there were bidirectional excitatory inputs between neurons that supply the aITB, a hip flexor, and those that supply the three femorotibialis muscle heads (iFT, mFT, and eFT), which act on the knee. However, the aITB and femorotibialis muscles are coactivated during the swing-extension phase of the step cycle (Jacobson and Hollyday, 1982a,b), so they do act synergistically during walking. This pattern of connectivity is similar to that observed in cats, where some motoneurons receive input from stretch- 
sensitive afferents that supply muscles acting at different joints, but that contract synchronously during some motor behaviors (Eccles et al., 1957; Eccles and Lundberg, 1958; Fritz et al., 1989). Therefore, as in other systems where sensory-motor connectivity has been studied, Ia connections in the chick correlate with the functional activation patterns of limb muscles and may aid in locomotion. In summary, the pattern of connections between muscle sensory and motor neurons in the chick embryo are consistent with functional and comparative predictions.

Development of sensory-motor connections in the absence of correlated neural activity. Earlier studies have provided indirect evidence that normal activity in muscle sensory neurons is not required for the formation of specific synaptic connections with motoneurons. The strongest evidence came from a study in which the axons of brachial motoneurons in tadpoles were interrupted by resection of the ventral root just before muscle spindle afferents began to establish their synaptic contacts with motoneurons (Frank, 1990). The connections therefore developed in the absence of neurogenic muscle movements. Even when motor axons eventually did regenerate, they did so nonspecifically, resulting in virtual absence of neurogenic muscle movements. Despite this disruption, sensory axons supplying different heads of the triceps brachii muscle all innervated the same subpopulation of brachial motoneurons, just as in normal frogs. The results show that sensory neurons can form synaptic connections with a specific class of motoneuron in the absence of coordinated muscle movements, arguing that at least some aspects of the specificity in this system are independent of normal activity patterns in the afferent fibers. The original identity of the motoneurons was not known, however, because they had regrown to random muscles, so it was not possible to determine whether the pattern of sensory-motor connections that formed in these animals was actually the correct one.

In the present study, we were able to test this idea directly by blocking neurogenic movements in a reversible way, so that the identity of motoneurons could be determined at the time synaptic connectivity patterns were assessed. Chick embryos were raised in the presence of dtc during the period that sensorymotor connections form. The dtc abolished neurogenic muscle contractions such that there was little change in muscle length and thus, presumably, no change in muscle spindle activity due to motoneuron discharge. Possible temporal correlations between patterns of activity in muscle sensory and motor neurons were therefore blocked. During the dtc treatment, a few small muscle contractions were observed, but these contractions did not significantly alter the joint angles and should not have altered the firing rate of spindle afferents. In addition to blocking neurogenic contractions, however, the doses of dtc used here dramatically reduced total levels of motoneuronal activity and blocked the normally correlated bursting patterns of particular motor pools (Landmesser and Szente, 1986). The mechanism underlying this effect is unknown, though dtc would presumably block cholinergic synapses in the spinal cord. Dtc can also act as a $\mathrm{GABA}_{\mathrm{A}}$ antagonist in the developing spinal cord (Bixby and Spitzer, 1982); picrotoxin, another $\mathrm{GABA}_{\mathrm{A}}$ antagonist, causes an initial increase and subsequent decrease in motoneuronal activity in the frog spinal cord (Peng and Frank, 1989). Therefore, dtc not only disrupts correlated activity, but probably also dramatically reduces total levels of activity in both muscle sensory and motor neurons. These data further support the idea that dtc treatment functionally interrupts the stretch reflex.

Chronic dtc treatment also blocks motoneuronal cell death that normally occurs during development (Laing and Prestige, 1978; Pittman and Oppenheim, 1979). If the motoneurons that normally die are specifically those that receive inappropriate sensory input, then the pattern of sensory-motor connections should be abnormal after dtc treatment. These treatments could therefore have disrupted synaptic connectivity in at least three separate ways: abolition of normal patterns of muscle afferent and motoneuronal activity, reduction in total levels of motoneuronal (and probably muscle afferent) activity, and blockade of motoneuronal death.

The major result of this study is that monosynaptic connections between sensory and motor neurons form in a precise and appropriate manner in the absence of correlated neural activity, in an environment of reduced total levels of activity, and in the absence of appreciable motoneuronal cell death. The one significant difference observed in the dtc-treated animals was that the amplitudes of composite EPSPs elicited in motoneurons upon stimulation of identified populations of muscle afferents were, on average, about twice as large as normal. This dramatic increase in EPSP amplitude was observed in 36 of the 48 sensory-motor pairs, and in all but one of the sensory-motor pairs where the average EPSP value in either the normal or the dtctreated group was greater than $0.2 \mathrm{mV}$.

There are several possible explanations that could account for the differences in monosynaptic EPSP amplitudes. In adult animals, altering the patterns or amounts of stretch reflex activity by axotomy (Gallego et al., 1979), tenotomy (Beranek and Hnik, 1959; Kozak and Westerman, 1961), spinal transection (Nelson and Mendell, 1979), or tetrodotoxin application (Manabe et al., 1989) has also been shown to increase the strength of sensory-motor connections. However, the cellular mechanisms responsible have not been determined. The increase in average EPSP amplitude in dtc-treated animals may be mediated either pre- or postsynaptically. It is known that blocking neural activity during development can induce neurons to form larger-thannormal axonal arborizations (Reh and Constantine-Paton, 1985; Callaway et al., 1987; Dahm and Landmesser, 1988; Shatz and Stryker, 1988; Sretavan et al., 1988). Perhaps muscle sensory afferents in dtc-treated animals sprout to form abnormally large numbers of synaptic connections with each motoneuron. This idea can be tested by labeling individual sensory neurons and counting the number of collateral branches and close appositions with motoneurons (the points of apposition are presumably sites of synaptic contact, as in Lichtman et al., 1984).

There are other testable hypotheses that do not involve extra synapses. For example, action potentials in sensory neuronal terminals might be broader in dtc-treated animals, leading to increased transmitter release at the sensory-motor synapse. Significant broadening of action potentials occurs following axotomy of sympathetic neurons (Kelly et al., 1986) and after NGF withdrawal from cultured DRG neurons (Chalazonitis et al., 1987). Alternatively, a postsynaptic change such as an increase in the motoneuronal input impedence or an increase in postsynaptic receptor density could increase synaptic potential amplitude. It will be of interest to determine if any of these possibilities account for the larger EPSPs in dtc-treated animals.

Another possibility is that dtc treatment not only abolishes motoneuronal cell death (as mentioned above), but also blocks the death of muscle sensory neurons. The total number of sensory axons in the dorsal roots of dtc-treated animals is not significantly different than normal (Oppenheim and Chu-Wang, 1983). However, muscle afferents represent only a small fraction 
of this total. If muscle afferents were specifically saved, there might not be an easily detectable change in the total number of axons in the dorsal roots, and the increased number of afferents in each muscle nerve could produce larger-than-normal EPSPs. This possibility is being tested by labeling and counting numbers of retrogradely labeled sensory neurons supplying particular muscles in normal and dtc-treated chicks.

Although the overall pattern of sensory-motor connections was normal, there were some subtle differences in the monosynaptic sensory-motor connections between dtc-treated and normal embryos. In 5 of the 48 types of sensory-motor pairs we tested, monosynaptic connections were observed in dtctreated animals that were not observed in normal animals. Three of the five pairs were between neurons that supply synergistic muscles. Sart and aITB are both hip flexors, and the Sart muscle also acts to extend the knee and is thus a synergist of mFT. In normal animals, fewer than $15 \%$ of the $\mathrm{mFT}$ and aITB motoneurons received Sart input, and none of the 13 Sart motoneurons were contacted by aITB afferents. However, in dtc-treated embryos, about half of the aITB and mFT motoneurons received monosynaptic Sart input, and nearly all Sart motoneurons were monosynaptically excited by aITB afferents. The other two abnormal sensory-motor pairs had a connectivity of about $30 \%$ in dtc-treated embryos, compared to none normally. We do not know whether these abnormal connections are present in normal embryos and are subsequently eliminated, or whether they form only as a result of the dtc treatments. In any case, even these "mistakes" are relatively small; each is substantially smaller than the corresponding homonymous connection.

The abnormal connections observed in dtc-treated animals represent the type of mistakes that might be expected if neural activity played an instructive role in the development of sensory-motor specificity. Activity might therefore provide a small amount of fine tuning of the connectivity pattern. Another possibility is that these abnormal connections might be the result of the blockade of motoneuronal cell death. Although the great majority of motoneurons saved by dtc treatments are located in or near the appropriate motor pools (Oppenheim, 1981), a small number might project to inappropriate muscles and might therefore express cell-surface molecular "labels" that do not match their peripheral projections. If muscle afferents used these cell-surface molecules to establish their correct connections with motoneurons, they would make functionally incorrect choices because of the incorrect peripheral projections of the motoneurons. In this way, naturally occurring cell death might act to sharpen the pattern of sensory-motor connectivity.

Even with the inclusion of these mistakes, however, Figure 6 shows that the overall pattern of stretch reflex connectivity in dtc-treated animals was remarkably similar to normal. These data indicate that neither patterned neural activity (or probably activity in general) nor motoneuronal cell death play a large role in the determination of stretch reflex connectivity. Spatial and temporal mechanisms also do not appear to dictate this pattern (see introductory remarks). Instead, it is likely that sensory afferents "choose" to contact the appropriate types of motoneurons based on some types of molecular recognition. These sensory-motor connections thus appear to develop differently than some of the connections in the visual and auditory pathways, for which patterned activity appears to be crucial (Hubel and Wiesel, 1965; Stryker and Harris, 1986; Knudsen, 1988). Are there any obvious differences between these 2 situations?

In regions of the nervous system where patterned activity is important, it is unlikely that individual postsynaptic cells are determined as to what type of input they will receive before they are contacted by presynaptic neuronal processes. For example, in the primary visual cortex, neurons in layer 4 are driven primarily by input from either the right or the left eye (Wiesel and Hubel, 1963; LeVay et al., 1977, 1978). During development, however, manipulations that change the pattern or amount of activity in one eye can dramatically alter the proportion of these neurons driven by that eye (Hubel and Wiesel, 1965, 1970; LeVay et al., 1977; Stryker and Harris, 1986). Layer 4 cells are therefore specified to receive information from a particular eye only after they are contacted by presynaptic neurons. In this context, patterns of neural activity may be necessary to insure that presynaptic cells responding to similar stimuli contact the same set of postsynaptic neurons.

In contrast, both pre- and postsynaptic neurons in the stretch reflex have already established connections with their peripheral targets before they synapse with each other in the spinal cord (Windle and Baxter, 1936; Landmesser and Morris, 1975; Frank and Westerfield, 1983; Smith, 1983). These neurons are thus likely to be already specified for a particular target muscle before they form their synaptic connections with each other. Populations of phenotypically determined sensory and motor neurons might bear different molecular labels such that ingrowing processes from sensory neurons could distinguish among motoneurons supplying different muscles. Perhaps in situations where pre- and postsynaptic cells are already determined prior to synaptogenesis, chemical recognition is sufficient to specify the pattern of synaptic connectivity.

\section{References}

Bekoff A (1976) Ontogeny of leg motor output in the chick embryo: a neural analysis. Brain Res 106:271-291.

Beranek R, Hnik P (1959) Long term effects of tenotomy on spinal monosynaptic response in the cat. Science 130:981-982.

Bixby J, Spitzer N (1982) The appearance and development of chemosensitivity in Rohon-Beard neurons of the Xenopus spinal cord. J Physiol (Lond) 330:513-536.

Brown AG, Fyffe REW (1978) The morphology of group Ia afferent fibre collaterals in the spinal cord of the cat. J Physiol (Lond) 274: 111-127.

Brown AG, Fyffe REW (1981) Direct observations on the contacts made between Ia afferent fibres and $\alpha$-motoneurones in the cat's lumbosacral spinal cord. J Physiol (Lond) 313:121-140.

Callaway E, Soha J, Van Essen D (1987) Competition favouring inactive over active motor neurons during synapse elimination. Nature 328:421-426.

Carmichael L (1926) The development of behavior in vertebrates experimentally removed from the influence of external stimulation. Psychol Rev 33:51-58.

Carmichael L (1927) A further study of the development of behavior in vertebrates experimentally removed from the influence of external stimulation. Psychol Rev 34:34 47.

Carpenter, Bergland R (1957) Excitation and conduction in immature nerve fibers of the developing chick. Am J Physiol 190:371-376.

Chalazonitis A, Peterson E, Crain S (1987) Nerve growth factor regulates the action potential duration of mature sensory neurons. Proc Natl Acad Sci USA 84:289-293.

Dahm LM, Landmesser LT (1988) The regulation of intramuscular nerve branching during normal development and following activity blockade. Dev Biol 130:621-644.

Davis B, Frank E, Johnson F, Scott S (1989) Development of central projections of lumbosacral sensory neurons in the chick. J Comp Neurol 279:556-566.

Debski E, Constantine-Paton M (1990) Activity-dependent tuning and the NMDA receptor. J Neurobiol 21:18-32. 
Eccles R, Lundberg A (1958) Integrative pattern of Ia synaptic actions on motoneurons of hip and knee muscles. J Physiol (Lond) 144:271298.

Eccles JC, Eccles RM, Lundberg A (1957) The convergence of monosynaptic excitatory afferents onto many different species of alpha motoneurones. J Physiol (Lond) 137:22-50.

Eide A-L, Janse JKS, Ribchester RR (1982) The effect of lesions in the neural crest on the formation of synaptic connexions in the embryonic chick spinal cord. J Physiol (Lond) 324:453-478.

Engberg I, Lundberg A (1969) An electromyographic analysis of muscular activity of the hindlimb of the cat during unrestrained locomotion. Acta Physiol Scand 75:614-630.

Fawcett JW, O'Leary DM (1985) The role of electrical activity in the formation of topographic maps in the nervous system. Trends Neurosci 8:201-206.

Frank E (1990) The formation of specific synaptic connections between muscle sensory and motor neurons in the absence of coordinated patterns of muscle activity. J Neurosci 10:2250-2260.

Frank E, Westerfield M (1982) Synaptic organization of sensory and motor neurones innervating triceps brachii muscles in the bullfrog. $J$ Physiol (Lond) 324:479-494.

Frank E, Westerfield M (1983) Development of sensory-motor synapses in the spinal cord of the frog. J Physiol (Lond) 343:593-610.

Fritz N, Illert M, De La Motte S, Reeh P, Saggau P (1989) Pattern of monosynaptic Ia connections in the cat forelimb. J Physiol (Lond) 419:321-351.

Gallego R, Kuno M, Nunez R, Snider WD (1979) Disuse enhances synaptic efficacy in spinal motoneurons. J Physiol (Lond) 291:191205.

Geren B (1955) The formation from the Schwann cell surface of myelin in the peripheral nerves of chick embryos. Exp Cell Res 7:558-562.

Hamburger V, Hamilton HC (1951) A series of normal stages in the development of the chick embryo. J Morphol 88:49-92.

Harrison RG (1904) An experimental study of the relation of the nervous system to the developing musculature in the embryo of the frog. Am J Anat 3:197-220.

Haverkamp LJ (1986) Anatomical and physiological development of the Xenopus embryonic motor system in the absence of neural activity. J Neurosci 6:1338-1348.

Haverkamp LJ, Oppenheim RW (1986) Behavioral development in the absence of neural activity: effects of chronic immobilization on amphibian embryos. J Neurosci 6:1332-1337.

Hollyday M (1980) Organization of motor pools in the chick lumbar lateral motor column. J Comp Neurol 194:143-170.

Honig MG (1982) The development of sensory projection patterns in embryonic chick hind limb. J Physiol (Lond) 330:175-202.

Hubel DG, Wiesel T (1965) Binocular interaction in striate cortex of kittens reared with an artificial squint. J Neurophysiol 28:1041-1059.

Hubel DH, Wiesel TN (1970) The period of susceptibility to the physiological effects of unilateral eye closure in kittens. J Physiol (Lond) 206:419-436.

Jacobson RD, Hollyday M (1982a) A behavioral and electromyographic study of walking in the chick. J Neurophysiol 48:238-256.

Jacobson R, Hollyday M (1982b) Electrically evoked walking and fictive locomotion in the chick. J Neurophysiol 48:257-270.

Jahr CE, Yoshioka K (1986) Ia afferent excitation of motoneurons in the in vitro new-born rat spinal cord is selectively antagonized by kynurenate. J Physiol (Lond) 370:515-530.

Jhaveri S, Frank E (1983) Central projections of the brachial nerve in bullfrogs: muscle and cutaneous afferents project to different regions of the spinal cord. J Comp Neurol 221:304-312.

Kelly M, Gordon T, Shapiro J, Smith P (1986) Axotomy affects calcium-sensitive potassium conductance in sympathetic neurones. Neurosci Lett 67:163-168.

Knudsen EI (1988) Sensitive and critical periods in the development of sound localization. In: From message to mind, directions in developmental neurobiology (Easter SS, Barald KF, Carlson BM, eds), pp 303-319. Sunderland, MA: Sinaucr.

Kozak W, Westerman RA (1961) Plastic changes in spinal monosynaptic responses from tenotomized muscles in cats. Nature 189:753755.

Laing NG, Prestige MC (1978) Prevention of spontaneous motoneurone death in chick embryos. J Physiol (Lond) 282:33P-34P.

Landmesser $\mathrm{L}$ (1978a) The distribution of motoneurons supplying chick hind limb muscles. J Physiol (Lond) 284:371-389.
Landmesser L (1978b) The development of motor projection patterns in the chick hind limb. J Physiol (Lond) 284:391-414.

Landmesser L, Morris DG (1975) The development of functional innervation in the hindlimb of the chick embryo. J Physiol (Lond) 249:301-326.

Landmesser LT, O'Donovan MJ (1984) Activation patterns of embryonic chick hind limb muscles recorded in ovo and in an isolated spinal cord preparation. J Physiol (Lond) 347:189-204.

Landmesser LT, Szente M (1986) Activation patterns of embryonic chick hind-limb muscles following blockade of activity and motoneurone cell death. J Physiol (Lond) 380:157-174.

Lee M, Koebbe M, O'Donovan M (1988) The development of sensorimotor synaptic connections in the lumbosacral cord of the chick embryo. J Neurosci 8:2530-2543.

Leonard R, Cohen D (1975) A cytoarchitectonic analysis of the spinal cord of the pigeon (Columbia livia). J Comp Neurol 163:159-180.

LeVay S, Hubel DH, Wiesel TN (1977) The development of ocular dominance columns in normal and visually deprived monkeys. $J$ Comp Neurol 191:1-51.

LeVay S, Stryker MP, Shatz CJ (1978) Ocular dominance columns and their development in layer IV of the cat's visual cortex: a quantitative study. J Comp Neurol 179:223-244.

Lichtman JW, Jhaveri S, Frank E (1984) Anatomical basis of specific connections between sensory axons and motor neurons in the bullfrog's brachial spinal cord. J Neurosci 4:1754-1763.

Manabe T, Kaneko S, Kuno M (1989) Disuse-induced enhancement of Ia synaptic transmission in spinal motoneurons of the rat. $J$ Neurosci 9:2455-2461.

Martin A (1979) A cytoarchitectonic scheme for the spinal cord of the domestic fowl, Gallus gallus domesticus: lumbar region. Acta Morphol Neerl Scand 17:105-117.

Matthews SA, Detwiler SR (1926) The reaction of Amblystoma embryos following prolonged treatment with chloretone. J Exp Zool 45: 279-292.

Mendell LM, Henneman E (1971) Terminals of single Ia fibers: location, density and distribution within a pool of 300 homogeneous motoneurons. J Neurophysiol 34:171-187.

Mendelson B, Frank E (1989) The formation of specific monosynaptic sensorimotor connections in chick embryos is not dependent on patterned neuronal activity or motoneuronal cell death. Soc Neurosci Abstr 15:126.

Mendelson B, Frank E (1990) Times of origin of brachial sensory neurons are not correlated with neuronal phenotype. J Comp Neurol 300:422-432.

Mendelson B, Koerber H, Frank E (1990) Development of cutaneous and proprioceptive afferent projections and motoneuronal dendrites in the chick spinal cord. Soc Neurosci Abstr 16:561.

Meyer RL (1983) Tetrodotoxin inhibits the formation of refined retinotopography in goldfish. Dev Brain Res 6:293-298.

Nelson SG, Mendell LM (1979) Enhancement in Ia-motoneuron synaptic transmission caudal to chronic spinal cord transection. I Neurophysiol 42:642-654.

Oppenheim R (1981) Cell death of motoneurons in the chick embryo spinal cord. V. Evidence on the role of cell death and neuromuscular function on the formation of specific peripheral connections. J Neurosci $1: 141-151$.

Oppenheim RW, Chu-Wang IW (1983) Aspects of naturally occurring motoneuron death in the chick spinal cord during embryonic development. In: Somatic and autonomic nerve-muscle interactions (Burnstock G, O'Brien R, Vrbova G, eds), pp 57-108. Amsterdam: Elsevier.

Peng Y, Frank E (1989) Activation of $\mathrm{GABA}_{\mathrm{A}}$ receptors causes presynaptic and postsynaptic inhibition at synapses between muscle spindle afferents and motoneurons in the spinal cord of bullfrogs. J Neurosci 9:1516-1522.

Pittman R, Oppenheim RW (1978) Neuromuscular blockade increases motoneurone survival during normal cell death in the chick embryo. Nature 271:364-366.

Pittman R, Oppenheim RW (1979) Cell death of motoneurons in the chick embryo spinal cord. IV. Evidence that a functional neuromuscular interaction is involved in the regulation of naturally occurring cell death and the stabilization of synapses. J Comp Neurol 187:425446.

Purves D, Lichtman JW (1984) Principles of neural development. Sunderland, MA: Sinauer. 
Raikow R (1985) Locomotor system. In: Form and function in birds (King A, McLelland J, eds), pp 57-147. London: Academic.

Ramon y Cajal S (1929) Studies on vertebrate neurogenesis. Springfield, IL: Thomas.

Reh T, Constantine-Paton M (1985) Eye-specific segregation requires neural activity in three-eyed Rana pipiens. J Neurosci 5:1132-1143.

Romanoff A (1960) The avian embryo: structural and functional development. New York: Macmillan.

Sah DWY, Frank E (1984) Regeneration of sensory-motor synapses in the spinal cord of the bullfrog. J Neurosci 4:2784-2791.

Sandell J, Masland R (1988) Photoconversion of some fluorescent markers to a diaminobenzidine product. J Histochem Cytochem 36: 555-559.

Schmidt JT, Edwards DL (1983) Activity sharpens the map during the regeneration of the retinotectal projection in goldfish. Brain Res 261:29-39.

Shatz C, Stryker M (1988) Prenatal tetrodotoxin infusion blocks segregation of retinogeniculate afferents. Science 242:87-91.

Smith CL (1983) The development and postnatal organization of primary afferent projections to the rat thoracic spinal cord. J Comp Neurol 220:29-43.

Sretavan D, Shatz C, Stryker M (1988) Modification of retinal ganglion cell axon morphology by prenatal infusion of tetrodotoxin. Nature 336:468-471.

Stryker MP, Harris WA (1986) Binocular impulse blockade prevents the formation of ocular dominance columns in cat visual cortex. J Neurosci 6:2117-2133.

Takahashi $\mathrm{T}$ (1984) Inhibitory miniature synaptic potentials in rat motoneurons. Proc R Soc Lond [Biol] 221:103-109.

Tosney KW, Landmesser LT (1985) Development of the major pathways for neurite outgrowth in the chick hindlimb. Dev Biol 109:193214.

Velumian AA (1984) Direct evidence for postsynaptic inhibition in the embryonic chick spinal cord. Dev Brain Res 14:229-239.

Visintini F, Levi-Montalcini R (1939) Relazione tra differenzazione strutturale e funzionale dei centri e delle vie nervose nell'embrione di pollo. Arch Suiss Neurol Psychiatr 43:1-45.

Wiesel TN, Hubel DH (1963) Single-cell responses in striate cortex of kittens deprived of vision in one eye. J Neurophysiol 26:10031017.

Windle WF, Baxter RE (1936) Development of reflex mechanisms in the spinal cord of albino rat embryos. Correlation between structure and function and comparisons with the cat and the chick. J Comp Neurol 63:189-209.

Windle WF, Orr DW (1934) The development of behavior in chick embryos: spinal cord structures correlated with early somatic motility. J Comp Neurol 60:287-307.

Wyman RJ (1974) Somatotopic connectivity or spccics recognition connectivity? In: Control of posture and locomotion (Stein RB, Pearson KB, Smith RS, Kedford JB, eds), pp 45-53. New York: Plenum. 